\title{
Do Charities Get More when They Ask More Often? Evidence from a Unique Field Experiment
}

\author{
Bas Donkers, Merel van Diepen, and Philip Hans Franses
}

\begin{tabular}{|l|l|}
\hline \multicolumn{2}{|l|}{ ERIM REPORT SERIES RESEARCH IN MANAGEMENT } \\
\hline ERIM Report Series reference number & ERS-2010-015-MKT \\
\hline Publication & February 2010 \\
\hline Number of pages & 32 \\
\hline Persistent paper URL & http://hdl.handle.net/1765/19423 \\
\hline Email address corresponding author & donkers@ese.eur.nl \\
\hline Address & Erasmus Research Institute of Management (ERIM) \\
& RSM Erasmus University / Erasmus School of Economics \\
& Erasmus Universiteit Rotterdam \\
& P.O.Box 1738 \\
& 3000 DR Rotterdam, The Netherlands \\
& Phone: + 31 10 408 1182 \\
& Fax: + 31 10 408 9640 \\
& Email: info@erim.eur.nl \\
& Internet: $\quad$ www.erim.eur.nl \\
\hline
\end{tabular}

Bibliographic data and classifications of all the ERIM reports are also available on the ERIM website: www.erim.eur.nl 


\section{ERASMUS RESEARCH INSTITUTE OF MANAGEMENT}

\section{REPORT SERIES}

\section{RESEARCH IN MANAGEMENT}

\begin{tabular}{|l|l|}
\hline ABSTRACT AND KEYWORDS \\
\hline Abstract & $\begin{array}{l}\text { Charitable organizations send out large volumes of direct mailings, soliciting for money in } \\
\text { support of many good causes. Without any request, donations are rarely made, and it is well } \\
\text { known that each request for money by a charity likely generates at least some revenues. } \\
\text { Whether a single request from a charity increases the total amount donated by an individual is } \\
\text { however unknown. Indeed, a response to one request can hurt responses to others. The net } \\
\text { effect is therefore not easily observable, certainly not when multiple charities address the same } \\
\text { individuals. } \\
\text { In this paper we alleviate these observational difficulties by carrying out a field experiment in } \\
\text { which five large charities cooperate. With the unique data that we collect, we study the impact of } \\
\text { sending more requests on total donations. } \\
\text { The results indicate that there is a negative competitive effect on requests from other charities, } \\
\text { but this effect dies out rapidly. Soon after the mailing has been sent, it is only a strong } \\
\text { cannibalization of the charity's own revenues that prevails. This empirical finding suggests the } \\
\text { important conclusion that not much coordination across charities is needed to increase } \\
\text { revenues. We also demonstrate that charities need sophisticated evaluation tools that do not } \\
\text { ignore the effects of cannibalization. } \\
\text { fundraising, competition, direct mailing, field experiment }\end{array}$ \\
\hline Classifications & $\begin{array}{l}\text { The ERIM Report Series is distributed through the following platforms: } \\
\text { Academic Repository at Erasmus University (DEAR), DEAR ERIM Series Portal } \\
\text { Social Science Research Network (SSRN), SSRN ERIM Series Webpage } \\
\text { Research Papers in Economics (REPEC), REPEC ERIM Series Webpage }\end{array}$ \\
\hline Availability & $\begin{array}{l}\text { The electronic versions of the papers in the ERIM report Series contain bibliographic metadata } \\
\text { by the following classification systems: } \\
\text { Library of Congress Classification, (LCC) LCC Webpage } \\
\text { Journal of Economic Literature, (JEL), JEL Webpage } \\
\text { ACM Computing Classification System CCS Webpage } \\
\text { Inspec Classification scheme (ICS), ICS Webpage }\end{array}$ \\
\hline
\end{tabular}




\title{
Do charities get more when they ask more often?
}

\author{
Evidence from a unique field experiment
}

\author{
Bas Donkers \\ Merel van Diepen \\ Philip Hans Franses \\ Erasmus University Rotterdam
}

February 2010

\begin{abstract}
Charitable organizations send out large volumes of direct mailings, soliciting for money in support of many good causes. Without any request, donations are rarely made, and it is well known that each request for money by a charity likely generates at least some revenues. Whether a single request from a charity increases the total amount donated by an individual is however unknown. Indeed, a response to one request can hurt responses to others. The net effect is therefore not easily observable, certainly not when multiple charities address the same individuals.

In this paper we alleviate these observational difficulties by carrying out a field experiment in which five large charities cooperate. With the unique data that we collect, we study the impact of sending more requests on total donations.

The results indicate that there is a negative competitive effect on requests from other charities, but this effect dies out rapidly. Soon after the mailing has been sent, it is only a strong cannibalization of the charity's own revenues that prevails. This empirical finding suggests the important conclusion that not much coordination across charities is needed to increase revenues. We also demonstrate that charities need sophisticated evaluation tools that do not ignore the effects of cannibalization.
\end{abstract}

Keywords: Fundraising, competition, direct mailing, field experiment. 


\section{Introduction}

The main purpose of a charity is to serve a good cause. This cannot be achieved without the necessary resources. As a consequence, fundraising has become a major activity for most charitable organizations. A whole range of marketing tools are used to do so, including charity auctions (Popkowski Leszczyc and Rothkopf, 2010), TV commercials, billboards, cause related marketing (Krishna and Rajan 2009), viral marketing campaigns, and social network site activities (Businessweek 2009). Despite potential merit of these tools, the final decision of a donor to make a donation is often triggered by a direct request. Direct mailings are therefore heavily used to solicit donations from the public. In 2008 the US public donated \$229.3 to charitable organizations in 2008 (AAFRC 2009), most often in response to direct mail requests.

Given the large number of charities in need of money, potential donors are bombarded with direct mailings that solicit a donation. Each of these mailings potentially triggers a donation, generating revenues for the charity sending the mailing. At the same time it is rather unlikely for an individual to make a donation without being asked (Andreoni 2006). Charities therefore have a clear incentive to send out more mailings. Importantly, charities have a tendency to more actively solicit donations when revenues are low, as is currently the case because of the financial crisis (Prizeman and McGee, 2009).

Charities should be able to assess whether sending more mailings is beneficial for themselves. ${ }^{1}$ As donors often receive mailings from multiple charities, it is unclear whether the charities jointly benefit in case they all increase the number of solicitations

\footnotetext{
${ }^{1}$ The fact that they send out more mailings in hard times seems at odds with optimal behavior. See Camerer et al. (1997) for a similar display of suboptimal behavior in case of New York cab drivers.
} 
they send. They will compete for the same donor's money and a request by one charity likely affects response behavior to requests from other charities, for example by increasing irritation (van Diepen et al. 2009a), budget effects and guilt (van Diepen et al. 2009b) or more in general through donor "fatigue" (Andreoni 2006). The net effect of sending more requests is therefore far from obvious. At the same time the aggregate level effects are of importance from a sector perspective and for policy makers, and these are also unclear.

This paper studies the impact of multiple charities when they all increase the number of mailings they send. The novelty of our approach is that we study this through a field experiment in cooperation with five large charitable organizations, which sent mailings to a subset of their donors upon our selection. These experimental mailings were added to the regular mailing schedules of these charities, enabling us to study in isolation the impact of sending more mailings by multiple charities. We can study the impact of these mailings on donation behavior in response to mailings received (almost) at the same time. More important, these mailings may have an impact well into the future as people remember past events. Therefore we also investigate the impact of these mailings on revenues generated by subsequent mailings. Note that to realistically study time dynamics, a survey cannot be used, even ignoring all kinds of other problems involved with self-stated donation behavior (Bekkers and Wiepking 2006, Burt and Popple 1998). Using the regular mailings from the charities is also problematic, as charities use target selection rules which are often based on past behavior. This biases results if no proper correction for target selection is made (Donkers et al. 2006). Consequently, our field 
experiment is a natural (but effortful) choice for data collection, as it balances realism and control (List and Reiley 2008).

Our paper starts with a brief review of the most important drivers of donor behavior. Unfortunately, none of these drivers - and their related theories - has clear cut predictions about donation behavior in response to requests from multiple charities at multiple moments in time. Next, the design of the field experiment is explained, followed by the results. The paper ends with implications for the charitable sector and a final conclusion.

\section{Theoretical background and predictions for competitive effects}

In the literature many motives for donating to charity are mentioned, see Bendapudi, Singh and Bendapudi (1996), Sargeant (1999) and Bekkers and Wiepking (2007) for reviews. The most studied motives that have relevance across multiple charities are 1) altruism 2) a feeling of joy of giving or 'warm glow’ 3) feelings of guilt and 4) prestige. These four motives can be dissected into two major groups. The first motive results in what is called pure altruism (Andreoni, 1989, 1990). The other three motives also result in altruism, but the underlying mechanisms are selfish as one obtains a good feeling (Andreoni 1989, 1990), prestige (Harbaugh 1998), or one is relieved from one’s guilt feelings (Dahl, Honea, and Manchanda 2003). Note that multiple motives might be at play at the same time, see for example Andreoni, Harbaugh, and Vesterlund (2007) or Harbaugh, Mayr, and Burghart (2007).

In terms of their implications for competitive effects, none of these theories have been extended thoroughly into the domain of donations to multiple charities, that is, when 
donors receive requests of multiple charities. Although such a theoretical exploration is not the aim of this paper, we do speculate on the implications of each motive for competitive effects below.

Starting with altruism, it is easily conceivable that donors care about the activities of each of the charities individually. For example, they value aid to children in third world countries but also the quality of life and life expectancy of people with a specific disease (who most likely live in western countries). So, in case donations are driven mainly by pure altruism, we expect little competitive effects across different charities. Some competitive interference might arise because of budget constraints, as these limit the total amount of money being donated.

Warm glow and guilt relief seem to be far less charity specific as any type of donation has the ability to generate warm glow or to relieve guilt. Evidence of a happy feeling resulting from donating money is presented by Dunn, Aknin and Norton (2008) and reviewed in Anik et al. (2010). For example, Dahl, Honea and Manchanda (2003, p.168) state that self-related guilt can be relieved by donating to charity. Here the cause of the guilt is unrelated to the type of charity, and hence a donation to any type of charity will suffice. Donating to charity can also be used as an act that licenses unrelated but less social or more selfish behavior, that is, guilt-inducing behavior (Khan and Dhar 2006). Again this is unlikely to depend on the type of charity receiving the donation. For these donation motives, charities are clear substitutes suggesting strong competitive effects.

The competitive effects for donations driven by the prestige motive are unclear. This mainly depends on how prestige is derived from donations to charity. In case it is the size of the amount donated, donors will specialize in donating to a single charity. In 
case it is important to be able to say "I donate to that charity as well”, then spreading donations across charities as much as possible will be optimal. In the data we will consider below, which concern the Netherlands, donations are mainly anonymous, so prestige can only be derived in an indirect manner, for example by the presence of a newsletter of a charity. Prestige will therefore mainly result in the spreading of donations across charities.

In terms of the impact of a mailing on future donation behavior to the same and to other charities, the current theories are even less informative. The needs of those in need will again increase over time, a feeling of warm glow might cool down, guilt will build up again and a newsletter will become outdated. Hence, all suggest that with the passing of time, a new donation will become desirable again. For the motives where the type of charity is relevant, a donation to a particular charity will decrease the marginal utility of donating to that charity, so on a next donation occasion other charities might be more preferred targets for a donation. For example, for prestige it holds that an outdated newsletter is replaced by a new one after the donation, while the prestige derived from the other charities is getting stale. Similarly, for the pure altruism motive a donation at least temporarily lowers the needs of that particular cause while the needs of other potential beneficiaries are still strong.

Finally, and in contrast to the motives to donate to charity, there are motives not to donate. In particular, requests from charities might induce irritation (Van Diepen, Donkers, and Franses 2009a) or cause donor fatigue (Andreoni 2006). As potential donors receive so many direct mailing solicitations - also perceived as junk mail - they become annoyed or are simply less sensitive to these appeals, and this lowers their 
responsiveness to such requests. This might affect donations triggered by mailings that are received simultaneously, but this effect will most likely also persist over time, hurting future donations as well. Note that Van Diepen, Donkers and Franses (2009a) show that, although individuals do claim to get irritated by direct mailing solicitation letters, they do not reduce the amount of money they give.

\section{Setup of the experiment}

To shed some light on this relatively unexplored domain of substitution of donations across charities and over time, we designed and implemented a natural field experiment in cooperation with five large charities in the Netherlands. To be able to uncover the effect of competitive mailings we vary the number of direct mailings in one week. We select individuals from the joint data set that is obtained after merging the databases of the five charities. ${ }^{2}$ Privacy regulations form a boundary condition, in that a charity is only allowed to store addresses of individuals who have donated at least once to that organization in the past. Hence, we only select previous donators of each charity to receive experimental mailings of that charity (see Karlan and List (2007) for a similar sampling frame).

The charities to which an individual donates vary across individuals. That is, individuals can be donator to 1, 2, 3, 4 or 5 of the charities that we consider and any charity combination is possible. Our experimental design guarantees that an individual who is donator to two charities can at most receive experimental mailings from these two charities. For example, an individual who is donator to charity A and B, and hence is only

\footnotetext{
${ }^{2}$ The databases were merged by a commercial firm that specializes in database and list management.
} 
on the mailing list of charity A and B, can only receive experimental mailings of charity A and B and not of charity C, as (s)he is not active with charity C.

Different experimental treatment conditions are created by varying the number of experimental mailings that subjects will receive. Each charity sends at most one experimental mailing to each individual in addition to the regular mailing campaigns that are scheduled throughout the year. The experimental mailings are extra mailings as compared to the charities' regular mailing strategies and the charities agreed (after our consultation) not to adjust their mailing strategies in response to the experimental mailings. Note that for the execution of the experiment we selected a week in which no regular mailings were planned by the five charities. Consequently, subjects will not receive more than one mailing of the same charity organization within that week. Competitive mail pressure thus only results from multiple mailings from other, nonparticipating organizations and from the experimental mailings. In Table 1 we depict the experimental design that is aimed at creating the necessary exogenous variation in direct mailings. It provides the proposed distribution of subjects over the various experimental treatments.

---Insert Table 1 around here---

As individuals who are donator to $n$ (with $n$ is $1,2,3,4$, or 5 ) of the five participating charities can only receive a maximum of $n$ experimental mailings, some entries in Table 1 are empty. Our field experiment consists of sending 21000 mailings to a total of 9000 subjects. Of course, there are various possible charity combinations for a 
particular number of charities. We choose to distribute the subjects uniformly across the different charity combinations, so that each of the five charities sends out 4200 experimental mailings. Within each charity combination, subjects are selected at random.

For the control group, we select 12000 subjects who will not receive additional mailings, consisting of 2400 subjects from each 'number of active charities' condition. Within each condition of the number of active charities, subjects are again distributed uniformly across different charity combinations and they will be drawn randomly from each combination.

\section{Data}

For this study we have access to the databases of five large charity organizations in the Netherlands, containing names and addresses of their donors. This enables us to create a unique dataset of direct mailings and (possible) donations at the individual level. Two charities are concerned with the health sector, two charities with the international aid sector and one charity with the social welfare sector. Our dataset covers mailings and donations during more than three and a half years, from January 2004 until August 2007, so we can create various potential explanatory variables based on each individual donor's track record.

\section{Sample}

We focus on a sub-sample of the population that meets the following criteria. First, we only consider individuals who have been active in the past 18 months, where "active" means that they have donated at least once in that period. Consultation with the involved 
charities has resulted in this definition, which they also use when performing analyses and selections on their databases.

Next, we eliminate individuals who have had an automatic transfer or membership of at least one of the charities in the past 18 months. The reason for this is that these individuals form a separate group of donators, and in particular the dynamic component of their behavior might be very different. ${ }^{3}$ Furthermore, these individuals are highly valuable to the charities and we were requested not to bother them with additional experimental mailings.

Next, charities keep track of individual mailing restrictions. Donators can communicate to the charities that they want to receive a maximum of two mailings per year, for example. Individuals with such restrictions are left out of consideration for obvious reasons. And finally, the commercial party that merged the databases also provided us with a list of individuals who died in the meantime. This data cleaning procedure results in 448281 potential experimental subjects, all of which are donator to at least one and at most to all five charities. The second column in Table 2 shows the distribution of these individuals across the number of active charities.

---Insert Table 2 around here---

\section{Implementation of the experimental design}

From the sample in Table 2 we draw our experimental subjects. Clearly, we are confronted with some upper bounds with regards to the numbers of potential

\footnotetext{
${ }^{3}$ Donating through an automatic transfer is a completely different dimension of charitable giving that raises many more interesting questions. We leave these for future research.
} 
experimental subjects. For example, the original design dictates a total of 5400 subjects that are donator to all five charities (see Table 1), while in practice we find that only 2278 of those subjects exist in our database. As our data consist of the full databases of the five charities, and thus contain information on the entire population of donators to these charities in the Netherlands, this is the very best that we can achieve. The 2278 subjects truly concern all individuals that are donator to all five charities.

A similar situation arises for the subjects with three or four active charities. For some charity combinations fewer individuals actually exist than we had anticipated in the experimental design. To ensure that each charity combination is equally represented under these restrictions and that each charity sends an equal amount of experimental mailings, we first substantially reduced the number of subjects in the control condition and when deemed necessary we also had a proportional reduction in the experimental design cells where mailings were sent. To have as many subjects as possible, this also resulted in a somewhat unbalanced distribution of subjects across the possible charity combinations. In our analyses we will take care of this unbalance.

Finally, even though we took the mailing restrictions that the charities supplied into account, these restrictions can change in the short period of time between the delivery of our subject selection to the charities and the actual week of the experiment. Combined with some administration issues this results in slight discrepancies between our adjusted experimental design and the final implemented subject distribution. Table 3 presents the final distribution of subjects in each of the design cells. A comparison with our adjusted design, which is presented in parentheses, shows that from the 17125 letters scheduled 17094 (99.8\%) were eventually sent. 
---Insert Table 3 around here---

\section{Timing of the experimental mailings}

The experimental mailings of the five charities were sent in the last week of March 2007. To represent reality as close as possible we decided not to send all experimental direct mailings on one single day. Although this would probably be the most effective way to measure competitive interference in the short run, consultation with the involved charity organizations convinced us that sending up to five mailings on a single day would raise suspicion with the experimental subjects, as this is an extremely rare situation in the Netherlands. This can be noticed from the third column in Table 2, which shows the average yearly direct mailing frequency of these five charities during our time span, for each number of active charities.

We find that individuals who are donator to all five charities receive on average one mailing every two weeks, for example, while all others receive mailings even less frequently. Furthermore, in our population, only $5 \%$ of the individuals have received multiple mailings of our five charities on the same day at least once in the past two years. However, for around $24 \%$ of the individuals there have been occasions in the past two years where they received multiple mailings of these charities in the same week. Thus, receiving multiple mailings of these charities in one week is a much more common situation than receiving them on one and the same day. Therefore, we decided to randomly distribute the experimental mailings for each individual over one week, to 
avoid subjects doubting whether the mailings would be real and guessing that something abnormal is going on. ${ }^{4}$

\section{Empirical results}

In this section we present the results of our analysis. First we study the impact of additional mailings on the total revenues of the charities, separated into the immediate response and the impact on potential future donations. As there are obviously more charities active than those who participate in the field experiment, we study in more detail the competitive effects of mailings across charities. This will enable us to extrapolate our findings towards the impact of sending more mailings at the sector level. To study these competitive effects, we distinguish between the impact of own and other charities' mailings, where "own" effects relate to the charity sending the mailing, and "other” effects to the other four charities.

To control for individual heterogeneity in donating behavior we include two RFM-type $^{5}$ variables describing past behavior, that is, the number of responses and the total donation in the year before the experiment. When studying the implications for an individual charity, these past behavior variables also distinguish between own and other effects. So, for example, when we model the response behavior to the experimental mailings, for an experimental mailing of charity 1 the number of own past responses concerns the donations made to charity 1 in the year before the experiment, while the number of other past responses concerns the donations made to charities 2, 3, 4 and 5. In

\footnotetext{
${ }^{4}$ The charities were asked to record donator contacts such as letters or phone calls that specifically mentioned high mail pressure in the weeks following the experimental mailings. No such events happened.

${ }^{5}$ RFM comprises Recency, Frequency and Monetary value of past behavior. RFM-type variables have been shown to be highly predictive of future behavior (Rossi, McCulloch and Allenby 1996).
} 
addition, we include dummy variables that indicate which charities are active for each individual as this could be indicative of an individual's attitude towards donating. ${ }^{6}$ Finally, we also include charity-specific intercepts to allow for systematic differences in response behavior towards charities. ${ }^{7}$

\section{Overall impact of sending more mailings}

The first step in our analysis is a study of the total revenues generated by the experimental mailings. The estimation results are presented in the first column of Table 4. The main result is that each experimental mailing generates 1.81 Euro in revenues, on average, so the short-run impact of mailings is positive. The controls have the expected signs, with donors who previously donated larger amounts of money and responded more often also donating more money in response to the requests in the experimental mailings. The more charities in the portfolio of a donor, the lower are the donations to the experimental mailings, as indicated by the negative charity activity dummies.

The next question is to what extent these short-run benefits come at the cost of lower future revenues. The second column of Table 4 presents the results of a regression of the revenues from subsequent mailings on the same set of predictors. Here we find a strong cannibalizing effect of the experimental mailings, with each mailing lowering future revenues by 1.21 Euros, representing a $62 \%$ loss of the initial gain. The control variables again have the expected signs, at least when they are significant. The final column presents a regression of the total revenues. The results are the combination of the

\footnotetext{
${ }^{6}$ Individuals who derive much utility from donating, independent of the underlying process, might have been more responsive to acquisition mailings of the charities in the past.

${ }^{7}$ The charity-specific intercepts relate to the dependent variable, for example response to a mailing of that charity. These differ from the dummy variables indicating whether a charity was active, as the charities do not send mailings to all their donators all the time.
} 
two earlier results, but now show that the net revenues of 0.69 Euro is still statistically significant. The net effect of more mailings for this set of charities together is therefore still positive and exceeds the average costs of sending a mailing and handling payment, which is about 0.51 Euro.

--- Insert Table 4 about here ---

\section{Short-run competitive impact of sending more mailings}

To learn about the impact of sending more mailings at the sector level, we need to see to what extent mailings of one charity influence the response to mailings from other charities. For this we focus on the donations to a single charity and study the impact of experimental mailings of that particular charity and those of the other charities, which we label as “own” and “other”, respectively. We again control for past donating behavior, also separated into own and other, and for the charities in a donor's portfolio.

The first competitive effects can occur at the time of the experimental mailings. Mailings from other charities potentially harm the revenues to a charity’s own mailing in terms of response rates and/or amounts donated. In this analysis each (non-) response to an experimental mailing represents an observation, so $\mathrm{N}=17094$ (mailings). To model response behavior to these donation requests, we use a Tobit II specification, which models the simultaneous decision of whether to respond or not and if so, with what amount (see Amemiya 1985 for details). Let $R_{i j}$ denote the dummy variable indicating whether donor $i$ responded to mailing $j\left(R_{i j}=1\right)$ or not $\left(R_{i j}=0\right)$. Furthermore, in case of a 
donation being made the amount donated is represented by $A_{i j}$. Let $X_{i j}$ denote the set of explanatory variables, then the Tobit II model is given by

$$
\begin{aligned}
& R_{i j}= \begin{cases}1 & \text { if } R_{i j}^{*}>0 \\
0 & \text { otherwise }\end{cases} \\
& A_{i j}= \begin{cases}A_{i j}^{*} & \text { if } R_{i j}^{*}>0 \\
0 & \text { otherwise }\end{cases}
\end{aligned}
$$

with

$$
\mathrm{R}_{\mathrm{ij}}^{*}=\mathrm{X}_{\mathrm{ij}} \beta^{\mathrm{R}}+\varepsilon_{\mathrm{ij}}^{\mathrm{R}}
$$

and

$$
\mathrm{A}_{\mathrm{ij}}^{*}=\mathrm{X}_{\mathrm{ij}} \beta^{\mathrm{A}}+\varepsilon_{\mathrm{ij}}^{\mathrm{A}}
$$

$$
\left(\varepsilon_{\mathrm{ij}}^{\mathrm{R}}, \varepsilon_{\mathrm{ij}}^{\mathrm{A}}\right)^{\mathrm{T}} \sim \mathrm{N}(0, \Sigma)
$$

The estimation results are presented in Table 5.

--- Insert Table 5 about here ---

The existence of competitive effects of mailings from other charities on donating behavior towards a charity's own mailing is highlighted by the significant negative effect of the number of other experimental mailings in both the response and the amount equation. Thus, there is competition as competitive mail pressure negatively affects donating behavior in response to a charity's mail both in terms of response probabilities and in terms of amounts donated. Note that the variable "experimental mailing own" has not been included as the responses are only observed for individuals receiving a mailing, so it always has the value 1. 
The parameter estimates for experimental mailings represent the effects on the latent response and amount (see equations $1-4$ ) and are thus not straightforward to interpret. Furthermore, the strong correlation between $\varepsilon_{R i}$ and $\varepsilon_{A i}$ complicates direct interpretation of the estimated coefficients, as the expected amount donated contains a correction for the selection bias (Heckman 1979).

To facilitate interpretation, we compute the effect of one extra mailing on the response probability and the expected donation, given the data. That is, for each mailing we compute the response probability and expected donation given that no competitive mailing versus. that one competitive mailing is received. For all other explanatory variables we substitute the observed values. This effect varies across the mailings and we report their average. We thus find that the effect of a competitive mailing on an individual's response probability to a mailing is $-0.36 \%$, compared to a predicted response rate of $13.39 \%$ for the situation without competitive mailings. For the amount donated we find that a competitive mailing reduces the donation conditional on response with $€ 0.25$ from the predicted baseline of $€ 16.38$ in case of no competitive mailings.

The impact on the expected revenue from sending out a mailing, which combines the effects on the response rate and the amount donated, is a reduction of $€ 0.10$ for an additional competitive mailing, starting from a predicted baseline of €2.41 without competitive mailings. To summarize, competitive mailings harm the revenues of a charity's own mailing. Otherwise put, the more mailings competitive charities send, the lower the revenues for the focal charity. As all experimental mailings were sent in one week, these results demonstrate competition between (effectively) simultaneous mailings. 
We now turn to the effects of our control variables. First of all, we find significantly positive effects of all past behavior variables, see again Table 5 . These variables capture attitudinal differences between donators, indicating that good donators in the past will also be good donators today. The own effects indicate a certain loyalty towards the focal charity, while the other effects indicate a more general attitude towards charitable donating. Plausibly, the own effects are larger than the other effects.

The dummy variables for activity of the charities all have a negative effect, most of which are significant. This means that given an individual's donation level, for which we control through the past behavior variables, his or her response probability and donations are lower if more charities are active and (s)he thus donates to more charities.

The charity-specific intercepts are not all equal. In particular, the intercept for charity 5 is much smaller than that for the other charities. This is due to an administrative error by this charity, which resulted in incorrect names being inserted in the letters, causing a very low response to this mailing. Note that this emphasizes that field experiments in this area are not easy to carry out. Overall, the intercepts in the amount equations are very small, resulting in highly negative predictions for the censored amount variable $A_{i j}^{*}$. However, as the correlation coefficient is very high (0.998), the Heckman selection correction (Amemiya 1985, Heckman 1979) ensures positive predictions for the donated amounts in all cases.

\section{Long-run competitive impact of sending more mailings}

We already noticed a reduction in future revenues by sending an additional mailing. In the short run we also found competitive effects of mailings of other charities. The open 
question now is: Is the negative impact on future revenues only driven by cannibalization of the revenues of the sending charity or do the competitive effects across charities persist over time? To answer this question we study the impact of competitive mailings on total revenues of a charity in a five month time frame after the experimental mailings were received. Note that all mailings sent out after the experiment are based on target selection. Importantly, however, these selections are independent of the experimental mailings and the responses to them.

--- Insert Table 6 about here ---

The results, presented in Table 6, show that there is strong cannibalization of the experimental mailings on future revenues of the charity sending the mailing. Thus, sending an extra mailing on top of the current mailing strategy reduces the total future donation with around $€ 1.51$. The effect of competitive mailings is not significant, so there is no competitive effect of experimental mailings in the long run. If anything, the effect is positive and this suggests synergies between mailings across charities over time. This is in line with findings of Van Diepen, Donkers and Franses (2009b) who also find synergies between charitable mailings over time. A possible explanation they offer is that mailings induce guilt that can be relieved by making a donation to a future mailing, independent of the charity under consideration.

\section{Sector level implications of sending more mailings}

The main conclusions from our field experiment are: 1) sending a mailing generates substantial revenues for the sending charity, 2) extra mailings of competitive charities 
reduce donations to simultaneous mailings of the focal charity, 3) over time there is strong cannibalization on the revenues of the charity that sends the mailing, and 4) competitive mailings have no effect on revenues from future mailings of the focal charity, so the effect in 2) is short lived.

When deciding whether to send out more mailings, a charity will balance the direct revenues with the direct costs of sending the mailing and the cannibalization on future revenues. At the sector level, the competitive influences also have to be taken into account. These competitive effects, however, are only limited to a fairly short timeframe as we only find negative competitive effects within the same week. ${ }^{8}$ The size of these competitive effects is also fairly limited, amounting to a revenue reduction of about $4 \%$ for the revenues of the charities sending out a mailing in the same week. At the current levels of mail pressure in the Netherlands, where households typically receive less than two mailings a week, on average, this lowers sector level revenues by about $10 \%$ of the revenues received from the mailing.

A charity maximizing its own revenues will stop mailing once the marginal additional revenues - the direct revenues minus revenues lost through cannibalization exceed the costs of sending out the mailing. Cannibalization is estimated to be about $63 \%$, so mailings are profitable for the charity as long as the costs are lower than $37 \%$ of the revenues or about 0.90 Euro. Accounting for sector-level effects, there is an additional loss of $10 \%$ of the revenues through competitive effects. The costs of a mailing should therefore not exceed $27 \%$ of revenues, which is about 0.65 Euro. With the actual current costs of a mailing of about 0.51 Euro, charities can still send out more mailings to

\footnotetext{
${ }^{8}$ Additional analyses on the response to the first mailing event after the experimental mailing already show insignificant competitive effects.
} 
increase their own revenues, without harming the total amount of money available for the good causes that the charitable sector supports as a whole.

\section{Conclusion}

In this paper we carried out a natural field experiment in cooperation with five of the largest charities in the Netherlands to study charity and sector-level implications of increasing mailing frequencies to donors. We studied the consequences of sending more mailings in the short run, that is, within the week in which the mailings were sent and in the long run, that is, a five month period following the receipt of the experimental mailings. ${ }^{9}$

Two of our findings stand out. First, the amount of cannibalization is really huge at almost $80 \%$ of net revenues, that is, after accounting for the costs of sending the mailing. This shows that the main competitor of a charity is the charity itself. Focusing only on short-term revenues might therefore be detrimental to the fundraising performance of a charity. In practice, however, charities often still use ROI measures that only link the direct revenues to the direct costs of sending the mailing ignoring the impact on future revenues. Improved evaluation tools are detailed in Blattberg, Kim and Neslin (2008, Chapter 28) and should be taken seriously by fundraising and marketing managers of charities.

Second, competition between charities is weak and very short-lived. This suggests that charities can work fairly independently in optimizing their mailing strategy. Only

\footnotetext{
${ }^{9}$ Note that although a five month period might not really qualify as long run, the fact that there is no detectable influence in that period makes it unlikely that competitive effects will be found using a longer horizon.
} 
during peak season in the days before Christmas, competition might really hurt revenues. At the same time, the short window in which a competitive effect prevails can also facilitate coordination between charities. Because competitive effects are short-lived, it will be fairly easy to divide weekly mailing opportunities across charities in order to minimize competitive interference, unlike the situation where competitive effects remain present for months.

The finding of short-lived competitive effects in combination with substantial cannibalization also has strong implications for further theory development. In particular, it shows that it does matter which charity receives the money, as otherwise a mailing should have a negative impact on the future revenues for all charities, not only the one sending the focal mailing. Theories that do not distinguish between the charities will have to be rejected in favor of those that do. As an example, a theory of warm glow would have to account for warm glow for each charity separately, as if there are separate mental accounts for each charity (Thaler 1985). This paper established this and other interesting patterns that a theory describing donation behavior across charities and over time will have to match. The development of such a theory is left for future research. 


\section{References}

AAFRC (2009) Giving USA 2008 - The Annual Report on Philanthropy for the Year 2008, Giving USA Foundation, Oak Brook, IL, USA.

Amemiya, Takeshi (1985), Advanced Econometrics, Cambridge, MA: Harvard University Press.

Andreoni, J., 2006. Philanthropy. In: Kolm, S.-C., Ythier, J.M. (Eds.), Handbook of Giving, Reciprocity and Altruism. North Holland, Amsterdam, pp. 1201-1269.

Andreoni, J., 1989: “Giving with Impure Altruism: Applications to Charity and Ricardian Equivalence,” Journal of Political Economy, 97, 1447-58

Andreoni, James (1990) "Impure Altruism and Donations to Public Goods: A Theory of Warm-Glow Giving”, Economic Journal, 100 (June), 464-477.

Andreoni, James, William T. Harbaugh and Lise Vesterlund (2007), Altruism in Experiments. The New Palgrave Dictionary of Economics, $2^{\text {nd }}$ edition, Steven N. Durlauf and Lawrence E. Blume Eds., Palgrave McMillan, Hampshire, England

Anik, Lalin, Lara B. Aknin, Michael I. Norton and Elizabeth W. Dunn (2010), Feeling good about giving: The Benefits (and Costs) of Self-Interested Charitable Behavior. In D.M. Oppenheimer \& C.Y. Olivola (Eds.), Experimental approaches to the study of charitable giving. In press.

Bekkers, René, and Pamala Wiepking (2006) "To Give or Not to Give: How Methodology is Destiny in Dutch Giving Data”, Nonprofit and Voluntary Sector Quarterly, 35, 533-540 
Bekkers, René, and Pamala Wiepking (2007) Generosity and Philanthropy: A Literature Review, Working paper, Department of Philanthropic Studies, Free University Amsterdam

Bendapudi, Neeli, Surendra N. Singh and Venkat Bendapudi (1996), “Enhancing Helping Behavior: An Integrative Framework for Promotion Planning”, Journal of Marketing, 60 (3), 33-49.

Blattberg, Robert C., Byung-Do Kim and Scott A. Neslin (2008) "Database Marketing. Analyzing and Managing Customers” Springer, New York

Burt, Christopher D. B., and Jennifer S. Popple (1998). Memorial distortions in donation data. Journal of Social Psychology, 138(6), 724-733.

Business Week (2009) Micropayments: Where Charity and Social Networks Meet, June 15 edition.

Camerer, Colin, Linda Babcock, George Loewenstein and Richard Thaler (1997) Labor Supply of New York City Cabdrivers: One Day at a Time, The Quarterly Journal of Economics, 112 (2), 407-441

Dahl, Darren W., Heather Honea and Rajesh V. Manchanda (2003), “The Nature of SelfReported Guilt in Consumption Contexts”, Marketing Letters, 14 (3), 159-171.

Donkers, Bas, Richard Paap, Jedid Jah Jonker and Philip Hans Franses (2006) Deriving Target Selection Rules from Endogenously Selected Samples, Journal of Applied Econometrics, 21, 549-562.

Dunn, Elizabeth W., Lara B. Aknin and Michael I. Norton (2008) Spending Money on Others Promotes Happiness, Science, 319, 1687-1688. 
Harbaugh, William T., (1998) "What do Donations Buy? A Model of Philanthropy Based on Prestige and Warm Glow,” Journal of Public Economics, 67, 269-284

Harbaugh, William T., Ulrich Mayr and Daniel R. Burghart (2007) “Neural Responses to Taxation and Voluntary Giving Reveal Motives for Charitable Donations,” Science, 316, 1622-1625

Heckman, James J. (1979) "Sample Selection Bias as a Specification Error" Econometrica, 47 (1), 153-161.

Karlan, Dean and John A. List (2007), "Does Price Matter in Charitable Giving? Evidence from a Large-Scale Natural Field Experiment”, American Economic Review, 97 (5), 1774-1793.

Khan, Uzma and Ravi Dhar (2006), “Licensing Effect in Consumer Choice,” Journal of Marketing Research, 43 (May), 259-66.

Krishna, Aradhna, and Uday Rajan (2009) Cause Marketing: Spillover Effects of CauseRelated Products in a Product Portfolio, Management Science, 55(9), 1469-1485

List, John A., and David Reiley (2008). Field experiments. In Steven N. Durlauf \& Lawrence E. Blume (Eds.), The New Palgrave Dictionary of Economics. Palgrave Macmillan.

Popkowski Leszczyc, Peter T.L. and Michael H. Rothkopf (2010) Charitable Motives and Bidding in Charity Auctions, Management Science, in press

Prizeman, Geraldine, and Siobhan McGee (2009) "Charitable Fundraising in an Economic Downturn”, The Centre for Nonprofit Management, Trinity College, University of Dublin. 
Rossi, Peter E., Robert E. McCulloch and Greg M. Allenby (1996), "The Value of Purchase History Data in Target Marketing”, Marketing Science, 15 (4), 321-340. Sargeant, Adrian (1999), “Charitable Giving: Towards a Model of Donor Behaviour”, Journal of Marketing Management, 15 (4), 215-238.

Thaler, Richard H. (1985), Mental Accounting and Consumer Choice, Marketing Science, 4(3), 199-214

Van Diepen, Merel, Bas Donkers and Philip Hans Franses (2009a) Does Irritation Induced by Charitable Direct Mailings Reduce Donations? International Journal of Research in Marketing, 26, 180-188

Van Diepen, Merel, Bas Donkers and Philip Hans Franses (2009b) Dynamic and Competitive Effects of Direct Mailings: A Charitable Giving Application, Journal of Marketing Research, 46 (1), 120-133 
Table 1.

Distribution of subjects over experimental conditions according to experimental design

\begin{tabular}{llrrrrrrr}
\hline & \multicolumn{3}{c}{ Number of active charities } & \multicolumn{2}{c}{ Total } \\
\hline Treatment & 1 & 2 & 3 & 4 & 5 & Subjects & Mailings \\
& 0 mailings & 2400 & 2400 & 2400 & 2400 & 2400 & 12000 & 0 \\
& 1 mailing & 600 & 600 & 600 & 600 & 600 & 3000 & 3000 \\
& 2 mailings & - & 600 & 600 & 600 & 600 & 2400 & 4800 \\
& 3 mailings & - & - & 600 & 600 & 600 & 1800 & 5400 \\
& 4 mailings & - & - & - & 600 & 600 & 1200 & 4800 \\
& 5 mailings & - & - & - & - & 600 & 600 & 3000 \\
\hline
\end{tabular}


Table 2.

Distribution of individuals across different numbers of active charities and average number of mailings received (per year)

\begin{tabular}{ccc}
\hline Number of active charities & Number of individuals & $\begin{array}{c}\text { Average number of mailings } \\
\text { received (per year) }\end{array}$ \\
\hline 1 & 341845 & 4.45 \\
2 & 72625 & 9.93 \\
3 & 22922 & 15.09 \\
4 & 8611 & 20.55 \\
5 & 2278 & 27.16 \\
\hline
\end{tabular}


Table 3.

Actual distribution of individuals across experimental conditions.

The intended distribution is in parentheses.

\begin{tabular}{|c|c|c|c|c|c|c|c|}
\hline \multirow[t]{2}{*}{ Treatment } & \multicolumn{5}{|c|}{ Number of active charities } & \multicolumn{2}{|c|}{ Total } \\
\hline & 1 & 2 & 3 & 4 & 5 & Subjects & Mailings \\
\hline \multirow[t]{2}{*}{0 mailings } & 2400 & 2401 & 2396 & 1772 & 383 & 9352 & 0 \\
\hline & $(2400)$ & $(2400)$ & (2394) & $(1770)$ & (383) & $(9347)$ & $(0)$ \\
\hline \multirow[t]{2}{*}{1 mailing } & 600 & 601 & 600 & 542 & 380 & 2723 & 2723 \\
\hline & $(600)$ & $(600)$ & $(600)$ & $(544)$ & (379) & $(2723)$ & $(2723)$ \\
\hline \multirow[t]{2}{*}{2 mailings } & - & 598 & 604 & 547 & 380 & 2129 & 4258 \\
\hline & & $(600)$ & $(600)$ & $(544)$ & (379) & (2123) & $(4246)$ \\
\hline \multirow[t]{2}{*}{3 mailings } & - & - & 594 & 541 & 381 & 1516 & 4548 \\
\hline & & & $(600)$ & $(544)$ & (379) & (1523) & $(4569)$ \\
\hline \multirow[t]{2}{*}{4 mailings } & - & - & - & 544 & 381 & 925 & 3700 \\
\hline & & & & (544) & (379) & (923) & (3692) \\
\hline \multirow[t]{3}{*}{5 mailings } & - & - & - & - & 373 & 373 & 1865 \\
\hline & & & & & (379) & (379) & (1895) \\
\hline & & & & & & $\begin{array}{c}17018 \\
(17018)\end{array}$ & $\begin{array}{c}17094 \\
(17125)\end{array}$ \\
\hline
\end{tabular}


Table 4.

Estimation results for total amount donated in Euros to 1) experimental mailings, 2) mailings after the experimental mailings, and 3) all these mailings

Revenues in response to

\begin{tabular}{lllllll} 
& \multicolumn{2}{c}{$\begin{array}{c}\text { Experimental } \\
\text { mailings }\end{array}$} & \multicolumn{2}{c}{$\begin{array}{c}\text { Mailings after } \\
\text { experiment }\end{array}$} & \multicolumn{2}{c}{ All mailings } \\
\hline Intercept & 0.213 & $(0.178)$ & $-1.789^{*}$ & $(0.937)$ & -1.577 & $(0.986)$ \\
\# experimental mailings & $1.812^{* * *}$ & $(0.059)$ & $-1.121^{* * *}$ & $(0.311)$ & $0.691^{* *}$ & $(0.327)$ \\
\# past responses & $0.130^{* * *}$ & $(0.023)$ & $1.463^{* * *}$ & $(0.122)$ & $1.594^{* * *}$ & $(0.128)$ \\
Total past donation & $0.014^{* * *}$ & $(0.001)$ & $0.225^{* * *}$ & $(0.003)$ & $0.239^{* * *}$ & $(0.004)$ \\
Active charity 1 & $-0.367^{* *}$ & $(0.157)$ & $6.274^{* * *}$ & $(0.825)$ & $5.906^{* * *}$ & $(0.868)$ \\
Active charity 2 & $-0.715^{* * *}$ & $(0.153)$ & 0.710 & $(0.805)$ & -0.005 & $(0.847)$ \\
Active charity 3 & -0.079 & $(0.153)$ & 0.062 & $(0.802)$ & -0.017 & $(0.843)$ \\
Active charity 4 & $-0.620^{* * *}$ & $(0.155)$ & $2.036^{* *}$ & $(0.816)$ & $1.416^{*}$ & $(0.859)$ \\
Active charity 5 & $-1.002^{* * *}$ & $(0.152)$ & -0.135 & $(0.796)$ & -1.136 & $(0.837)$ \\
\hline
\end{tabular}

*,**,***: significant at a $10 \%, 5 \%$, and $1 \%$ level, respectively. 
Table 5.

Estimation results for the Tobit II model for donating behavior in response to the experimental mailings (standard errors are in parentheses)

\begin{tabular}{|c|c|c|c|c|}
\hline \multirow[b]{2}{*}{ Intercept charity 1} & \multicolumn{2}{|c|}{ Response equation $\left(\beta^{R}\right)$} & \multicolumn{2}{|c|}{ Amount equation $\left(\beta^{A}\right)$} \\
\hline & $-1.082 * * *$ & $(0.056)$ & $-21.980 * * *$ & $(1.471)$ \\
\hline Intercept charity 2 & $-1.392 * * *$ & $(0.057)$ & $-29.458 * * *$ & $(1.534)$ \\
\hline Intercept charity 3 & $-1.068 * * *$ & $(0.054)$ & $-21.965 * * *$ & $(1.431)$ \\
\hline Intercept charity 4 & $-1.061 * * *$ & $(0.054)$ & $-22.095 * * *$ & $(1.432)$ \\
\hline Intercept charity 5 & $-2.356 * * *$ & $(0.076)$ & $-51.232 * * *$ & $(2.147)$ \\
\hline \# experimental mailings other & $-0.019 *$ & $(0.013)$ & $-0.620 * *$ & $(0.304)$ \\
\hline \# past responses own & $0.094 * * *$ & $(0.008)$ & $1.436 * * *$ & $(0.199)$ \\
\hline \# past responses other & $0.054 * * *$ & $(0.004)$ & $1.082 * * *$ & $(0.100)$ \\
\hline Total past donation own & $0.001^{* * *}$ & $(0.000)$ & $0.074^{* * *}$ & $(0.004)$ \\
\hline Total past donation other & $0.000 * *$ & $(0.000)$ & $0.020 * * *$ & $(0.002)$ \\
\hline Active charity 1 & $-0.049 *$ & $(0.035)$ & $-1.187 *$ & $(0.855)$ \\
\hline Active charity 2 & $-0.098 * * *$ & $(0.033)$ & $-2.101 * * *$ & $(0.803)$ \\
\hline Active charity 3 & -0.028 & $(0.034)$ & -0.258 & $(0.840)$ \\
\hline Active charity 4 & $-0.107 * * *$ & $(0.036)$ & $-2.702 * * *$ & $(0.877)$ \\
\hline Active charity 5 & $-0.074 * * *$ & $(0.030)$ & $-1.861 * * *$ & $(0.742)$ \\
\hline$\sigma$ & $23.988 * * *$ & $(0.411)$ & & \\
\hline$\rho$ & $0.998 * * *$ & $(0.000)$ & & \\
\hline
\end{tabular}

*,**,***: significant at a $10 \%, 5 \%$, and $1 \%$ level, respectively. 
Table 6:

Estimation results for the total donation in the five months after the experimental mailings (standard errors are in parentheses)

\begin{tabular}{|c|c|c|}
\hline Intercept charity 1 & $5.871 * * *$ & $(0.484)$ \\
\hline Intercept charity 2 & -0.691 & $(0.473)$ \\
\hline Intercept charity 3 & $-1.481 * * *$ & $(0.469)$ \\
\hline Intercept charity 4 & $1.804 * * *$ & $(0.462)$ \\
\hline Intercept charity 5 & -0.743 & $(0.461)$ \\
\hline experimental mailing own & $-1.514 * * *$ & $(0.282)$ \\
\hline \# experimental mailings other & 0.105 & $(0.126)$ \\
\hline \# past responses own & $1.944^{* * *}$ & $(0.092)$ \\
\hline \# past responses other & $-0.166 * * *$ & $(0.044)$ \\
\hline Total past donation own & $0.178 * * *$ & $(0.002)$ \\
\hline Total past donation other & $0.017 * * *$ & $(0.001)$ \\
\hline Active charity 1 & -0.023 & $(0.283)$ \\
\hline Active charity 2 & 0.282 & $(0.280)$ \\
\hline Active charity 3 & 0.352 & $(0.276)$ \\
\hline Active charity 4 & -0.250 & (0.289) \\
\hline Active charity 5 & 0.005 & $(0.274)$ \\
\hline
\end{tabular}

*,**,***: significant at a $10 \%, 5 \%$, and $1 \%$ level, respectively. 


\section{Publications in the Report Series Research* in Management}

\section{ERIM Research Program: "Marketing"}

2010

Deviation Among Technology Reviews: An Informative Enrichment of Technology Evolution Theory for Marketing Ashish Sood and Stefan Stremersch ERS-2010-005-MKT

http://hdl.handle.net/1765/17766

Perceptual maps: the good, the bad and the ugly John Gower, Patrick Groenen, Michel Van de Velden and Karen Vines ERS-2010-011-MKT

http://hdl.handle.net/1765/18462

Do Charities Get More when They Ask More Often? Evidence from a Unique Field Experiment Bas Donkers, Merel van Diepen, and Philip Hans Franses

ERS-2010-015-MKT

http://hdl.handle.net/1765/19423

A complete overview of the ERIM Report Series Research in Management: https://ep.eur.nl/handle/1765/1

ERIM Research Programs:

LIS Business Processes, Logistics and Information Systems

ORG Organizing for Performance

MKT Marketing

F\&A Finance and Accounting

STR Strategy and Entrepreneurship 